\title{
An Alternative to the Dominant Tradition
}

I

\section{What Is a Right?}

What, EXACTLY, IS A RIGHT? Surprisingly, there is no definition on which all rights theorists will agree, and many simply take the concept for granted. Most contemporary writers in the field define rights as claims; some see them not simply as claims, but as claims to which there are reciprocal duties or obligations. Wesley Hohfeld asks, regarding the term 'right', "what clue do we find ... toward limiting the word in question to a definite and appropriate meaning?" His answer is, "That clue lies in the correlative "duty'."1 In Thomson's version, "X's having a claim [against Y] is equivalent to Y's being under a duty."'2 This does not mean that every duty is a duty to satisfy a rights-claim. Supposing that there is a moral duty to be charitable, no one has a right to charity. Nevertheless, as Alan Gewirth puts it, "There is a logical correlativity between ' $\mathrm{A}$ has a right to $\mathrm{X}$ ' on the one hand, and, on the other, 'Other persons ought to [i.e., have a duty to] refrain from interfering with A's having $\mathrm{X}$ and ought, also, under certain circumstances, to assist $\mathrm{A}$ to have $\mathrm{X}^{\prime}{ }^{3}$

Whether or not they agree that there is a duty correlative to every right, many others also speak of rights as claims. But there are some problems with this usage. For instance, despite Hohfeld's use of 'claim' as a synonym for 'right' in what he calls the strictest sense, he distinguishes between claim-rights and the kinds of rights he calls powers and liberties; and there are others who conceive rights as essentially liberties.

Moreover, there is an ambiguity in the way the word 'claim' is used: we can be said to have a claim and also to make or assert a 
claim, with the somewhat confusing consequence that we can claim something to which we have no claim. Thus, some hold that a right is a justified or, as Feinberg prefers to say, a valid claim. ${ }^{4}$ I prefer a different solution, which avoids both sorts of problem.

One who "has a right," in the conventional sense of this expression, is entitled to possess something, to act in a particular way, or to be accorded a particular sort of treatment. That is, she or he has an entitlement. Virginia Held contends that "[m]oral rights are stringent entitlements yielded by valid moral principles." 5 But if rights are entitlements, what is the relation between rights and duties? Should we define a right as an entitlement to which there is a correlative duty? Is this duty in some sense constitutive of the right? Or is it only implied by an entitlement that has been established as a right independently?

Not every entitlement counts as a right. One may be entitled to praise for doing something well, but nobody would call this entitlement a right. For it to be a right, the praise would have to be obligatory, owed. It would be a duty. But duties are specific actions; for example, Thomson's illustration of her definition of a right: "A has a claim against B that B stay off A's land." But there can be more than one action whose performance is required by a given rights-entitlement (if $\mathrm{A}$ has a right to his land-is entitled to its possession and use-B may also have a duty not to erect any structure that will block A's access to his land). And circumstances could arise in which additional actions, as yet unanticipated, would be called for. In addition, there are entitlements that can be fulfilled in alternative ways. (If there is a right to health care, it can be satisfied by providing a national health system like Canada's, or by making private health care or private health insurance affordable, or by passing a law requiring all employers to provide health insurance for their employees and their families-plus making some provision for care of the unemployed and their families.) In some cases, precisely which actions it is a duty to perform in order to satisfy a given entitlement is a matter of dispute. This is an important dimension of the struggle over "affirmative action" in the United States today. It is coming to be accepted that women and members of ethnic minorities have a right to be treated fairly. Some people (including writers and lawyers who 
have testified before the United States Supreme Court) say that people in both categories, who have higher rates of unemployment, seldom occupy high-level positions in business, industry, or government, and receive proportionately fewer secondary-school diplomas or college or university degrees, are thus disadvantaged because they have been unfairly discriminated against historically and, in some cases, continue to be discriminated against. (For instance, at least in our large cities, black children on average attend schools that are more crowded, older, less well kept, and more poorly equipped than do white children.) Therefore, some contend, it is only fair to give those who fall into these categories preference in such things as hiring and college, graduate, and professional school admissions, at least in cases where they are as well qualified as other, nonminority candidates. (Some would say that different criteria should be applied to them.) Others, however, insist that this so-called "affirmative action," as preferential treatment, constitutes "reverse discrimination," and is inherently unfair. ${ }^{6}$ If we do take fair treatment to be a right, what, in such cases, is the duty correlative to this right? If we have no generally accepted way of satisfying this entitlement, should we, on the grounds that there is no correlative duty, deny that it is or can be a right?

I suggest that we need to put the issue in a somewhat different perspective. In any society in which the institution of rights is operative, there is a general obligation to acknowledge rights and to respect them whether or not we are called upon to express this attitude in overt behavior. And when we are called upon to implement a right, to satisfy an entitlement that counts as a right, whatever action we choose to perform, this attitude should govern our performance. We ought to act out of respect for the rights-entitlement in question, or, as Kant might put it, for the sake of respecting it, and not for any other reason. It is this, rather than the act per se (or, in some cases, rather than any particular act), that is called for by the exercise of the right. Thus, instead of saying that there are duties correlative to rights-entitlements, I prefer to say that there is a correlative obligation to respect them, binding upon all. ${ }^{7}$ It is this obligation that distinguishes an entitlement that is a right from other entitlements. Apart from the obligation of all to respect it, which entails implementing this respect in action when one is in a position to do so, the entitlement 
would not be a right. Therefore, the norms making respect for it obligatory are constitutive of the right. To put it another way: the rights-entitlement and the obligation to respect it are constitutive of each other. This obligation is, of course, a duty; but stating it in the language I propose avoids the connotation of specificity that has come to be attached to the latter word, at least as it is employed in the literature of rights-theory.

A right, then, involves both an entitlement and a correlative obligation to respect it, and we could define a right as consisting of the two in their mutual relation. Strictly, a right is a relation-an institutionalized relation-between an entitlement and an obligation. To be accurate, we should speak of what we now call 'rights' as 'rights-entitlements'. However, the conventional usage, in which rights-entitlements are called 'rights', is almost unavoidable, and I shall use whichever term is clear in any particular context. But the conjunction of entitlement and obligation in an institutionalized rights-relation is not the whole story.

As both Gewirth and Margaret MacDonald remind us, the words 'entitlement' and 'obligation' (and the name 'right' as well) are not simply descriptive terms. ${ }^{8}$ To say " $\mathrm{X}$ is entitled" or " $\mathrm{X}$ is obligated" is not to make a bare statement of fact; each of these statements has a prescriptive dimension. ' $\mathrm{X}$ is entitled' means that she ought to be permitted to do or to have whatever she is entitled to; ' $\mathrm{X}$ is obligated' means that he ought somehow to fulfill the obligation, to act so as to implement it or behave in such a way as to show that he acknowledges it. These meanings are established by the social norms. But they are not merely descriptive. They are prescriptive, directing us to behave in certain ways. The norms determining the entitlements and obligations associated with the institution and language of rights are rules of conduct, evolved by the community to govern certain of the relations among its members and carrying the community's authority. This authority is the source of their normative force. All who have internalized these normative principles are aware of their prescriptive character. They understand or feel (or are aware that they ought to do so) that they and everyone else should govern themselves by them and that it would be wrong not to. The language of rights expresses this understanding.

Insofar as they are internalized, therefore, and operative in gov- 
erning the behavior and expectations of the members of the community, it is the social norms governing the institution of rights that effectively define and put into operation the entitlements and the obligations of those who participate in rights-relations. These norms are part of the attitude of the generalized other, the attitude of a community in which there are rights that are actually operative. Thus, the full definition of a right must include another term. It is not only a relation between an entitlement and an obligation to respect it. It is also a relation that exists in virtue of-hence, in relation to-the attitude of a generalized other. The rights-relation is a triadic one. Viewed in one way, the terms of this relation are the normative attitude, the entitlement, and the obligation it jointly establishes. It may also be seen as a relation between a community whose attitude encompasses rights-norms and any pair of its members, one in the position of entitlement, the other in that of being obligated to respect it. However, in principle every member of the community occupies both positions or roles: that of having the defined entitlement and that of being obligated to respect it, either role to be enacted as circumstances warrant. This is to say that the rights-relation is a mutual relation between each member of a community in which rightsnorms are operative and each of the others, a relation that obtains in virtue of their sharing the attitude of a generalized other.

As a consequence of this analysis of rights, I reject all four of the interrelated principles or assumptions discussed in Chapter 1. I would like to explain why in some detail and show some of the ramifications and implications of my view. In the interest of clarity, I shall focus on each principle separately, but due to their interrelations, the treatment of each will involve discussion of others. I shall deal with them in the following order: the principle of a priorism, i.e., the assumption that rights are either self-evident or independent of social communities; the principle of adversarialism, i.e., the assumption that they are claims against other persons or against society or the State; the principle of essentialism, i.e., the assumption that the ground for the possession of 
rights lies in some essential trait of human (or quasi-human) nature as such; and the principle of individualism, i.e., the assumption that rights are inherently and exclusively properties of individuals.

\section{$A$ Priorism and the Concept of Universal Rights}

Plainly, being conferred by a community through the establishment of norms, rights are not a priori. This has an important consequence. Linked to the assumption that rights are antecedent to membership in any community and also to the attribution of rights in virtue of human nature or personhood is the assertion, common to all natural rights theories, of the existence of universal human rights. But, on the proposed analysis, for a right to be operative, i.e., for it to exist, it must be institutionalized in a community, however wide or narrow that community may be; thus, the thesis that human rights are antecedent to society or that their existence is not dependent on rights-bearers' belonging to any community is falsified by definition. If any set of norms were universally operative among all humans, all humans would, in this respect even if not in others, constitute a single, universal normative community. If these norms were rights-norms, or included rights-norms among them, the rights these norms establish would be, ipso facto, universal human rights. Every human would participate in them, both as having the institutionalized entitlements and as being obligated to respect them, regardless of any other community affiliations. But they would still be operative in a community. And, clearly, some rights, such as the right to vote, which are linked to cultural institutions, are community based.

Mead at times suggests not only that there are universal rights, but also that to say that there is any particular right is to say that it is universal: "[R]ights exist," he says, "only in so far as they are acknowledged, and only to the extent that those who claim them acknowledge them in the person of others. That is, no man can claim a right which he does not recognize for others"' (MT 13). On my proposed analysis, which derives in part from Mead, this is necessarily the case. Mead goes on to say, "No man can claim a right who does not at the same time affirm his own obligation to respect that right in all others" (MT 13; emphasis added). This 
implies that for anyone to claim or attribute a right is to affirm its universality, its universal existence. In practice, however, this cannot be the case, since a right will be operative-it will exist-only among those who do, in fact, share in the general attitude expressed by Mead's statement. In saying that there is a right, those who have the attitude governing it may mean to extend it to all others, and we would expect them to treat all others as if they were participants in the social institution of rights. But whatever rights we consider, there may be (and almost certainly are) communities in which those rights are neither recognized nor respected. This is to say that, while we may judge that certain rights ought to be universal, and even though those of us who have internalized rights-norms may act as though the rights we respect are universal, these and all other rights are fully operative only among those who have internalized the normative attitude of a community in which such rights are institutionalized. However, all who respect a given right and who claim it for themselves and attribute it to others constitute such a community, a community of the kind I call a 'normative community,' which is constituted by all who share a common set of norms. Regardless of geography, all who respect a given right belong to such a community. Moreover, all who respect rights of any kind, whichever rights those may be, constitute an extended community in which rights in general are recognized and respected. Furthermore, the perspective that they share (the attitude of a generalized other) enables them to discuss rights and deliberate as to which rights ought-or perhaps ought not-to be operative, either in their own communities or, universally, in all communities.

There is, as yet, no universal human community, even if we believe there ought to be. Even though the United Nations Declarations prescribe rights for all humans and all peoples, these rights are not universally operative- at least not yet. The claim to have a right that is not operative in a social community to which one belongs (for example, for a woman to claim equal rights with men in a patriarchal society) can mean only that the one who is making the claim believes that she and all others ought to have that right. Part of my theory of operative rights is an argument for universal rights (in my own terminology, 'generic rights'). However, I define these not in terms of a universal normative 
community, the possibility of which I doubt, but as rights (entitlements with a correlative obligation to respect them) that ought to be operative in every normative community. The specification of 'normative community' has a particular significance.

Very briefly summarized, my argument is this: The existence of social norms, hence, of normative communities, is a prerequisite of human life as we know it. All intelligible communication, all meaningful social behavior, all coordinated social interaction is norm-governed. Being the product of communicative interactions among the members of a community, social norms can be established and perpetuated only by being accepted and applied in the community. In addition, in order to apply the norms, one must determine, first, whether they are really applicable to the situation at hand and, if so, in what way or ways and, second, how they should be applied. It is in this process that norms evolve and change. For norms to arise in the first place, then, and for them to carry the authority of a community, requires the participation of that community's members in their institution: it requires that they exercise their own personal authority in this process. Therefore, freedom to exercise this authority in the life of the community, the sphere in which the norms evolve and are reinforced or modified, is a necessary condition of the evolution and continuing existence of a normative community. Normative community being a necessary condition of human existence, a right of personal authority ought to be established in every community. But for norms to continue to be operative, they must be recurrently applied and, if their application is not to be an involuntary performance (in which case the norms are likely to be rejected) or an empty exercise (in which case they will lapse into desuetude and lose their authority), those persons who are called on or are in a position to apply them must be allowed to do so in accordance with their own judgment and in the light of their own experience. That is, they must be allowed to judge the norms autonomously. Therefore, in addition to the right of personal authority, a right of personal autonomy should be made operative in the ongoing life of every normative community. I call these the fundamental generic rights: fundamental in that they are necessary conditions for the continuing existence and stability of any nor- 
mative community, and generic in the sense that they ought to be made universally operative.

Rights are often taken to be absolute, as well as universal, especially by those who view them as a priori and unconditioned by the social process to which they are supposed to apply. But the prescriptive force - the authority and presumed applicability - of rights-norms cannot be absolute or unquestionable. In the first place, more than one right may be applicable in a given situation, and these may conflict, so that the exercise of rights by one party may have to be at the expense of those of another. In an issue that was brought before the courts in the United States, so-called "hate speech" was held to be protected by the right of freedom of expression enshrined in the Bill of Rights. Against this, it was argued that such utterances infringe the right of those toward whom they are directed to be free of harassment. Plainly, these rights cannot prevail together, and a judgment is called for as to which should take precedence.

Rights may also come into conflict with other values. Especially by those who take them to exist a priori, rights are taken to be "trumps," which outweigh all contending principles in regulating social life. But other normative values may be judged in some situations to outweigh any given right. Even in communities where personal liberty is respected as a basic rights-entitlement, we do not hesitate to limit the liberty of a convicted criminal. More important, like all other forms of norm-governed social behavior, rights are living institutions. In any situation in which they come into play, not only may we sometimes find other norms to be applicable; we can also develop new understandings of what is at stake, new interpretations of or new insights into features of the situation or of the norms themselves or their consequences. We take these interpretations and insights into account in our personal deliberations and sometimes we introduce them into the social dialogue. This is to say that the operation of social norms does not preclude criticism (and, I contend, there can and ought to be a right or even an obligation of criticism). In actual fact, critical deliberation is part of the process in which norms are instituted, perpetuated, and modified. One place this process is systematically carried on is in the law courts. But not all social norms are ever enacted into law (think of the norms 
governing grammar and usage or those of dress), and there can be laws that never acquire the authority of the community at large so that they never become operative as social norms. Others lose that authority, so that even though they were once operative, they cease to be so. In the United States, for instance, the laws and norms governing minority rights have yet to keep pace with one another. Many people who would grant minorities equal treatment and who do so in their private lives or their own local communities have fought for legislation guaranteeing racial, sexual, and ethnic equality; yet there are laws establishing minority rights, such as the laws guaranteeing equal education and those prohibiting discrimination in the sale and rental of housing, that are openly flouted.

\section{Adversarialism}

One of the lessons we learn from Mead is that social norms, being attitudes of a "generalized other," enable those among whom they are operative to view the acts, things, and situations to which they are applicable in the same general perspective, allowing each of them to understand the responses of others even if these others have different social positions and roles. It is because we share the attitude of a generalized other that each of us understands his or her place and role in the complex social order in which we are located. Only by sharing a common understanding of the diverse roles in their mutual interrelatedness can we know how to play our own. The special feature of rights-norms is that, by their content, they confer upon all who are governed by them the reciprocal roles they establish, that of having rights (or rightsentitlements), and that of being obligated to respect those rights. In so doing, they establish a basis for mutual identification. Since for me to understand that I have a right is to understand you to have it as well, and vice versa, I also understand that if any of us can be arbitrarily deprived of this right, it is not really a right. I can see, therefore, that it is in my interest to protect your rights and I can show you that it is in your interest to protect mine. This mutuality that is inherent in rights-relations as I see them (and here, of course, I follow Mead) is directly contrary to the adversarial character attributed to them by those who conceive 
rights as claims against others. Not that one cannot bring suit against others to compel them to supply that to which one is entitled by right. But the unforced implementation of the rightsnorms that are operative in everyday life is both a cause and a sign of social cohesion. A community in which those rights I have identified as fundamental and generic are operative, which I call a 'community of dialogic reciprocity', is one in which, regardless of their differences, each member recognizes and accepts as rights the autonomy and authority of all. ${ }^{9}$ In such a community, could it exist, each member would understand that to respect the autonomy and authority of others is to protect one's own. Did such a community exist, it would embody the democratic ideal of unity in diversity: an ideal of the acceptance of difference, whether of opinion or of identity, together with a sharing of responsibility for decision-making and a willingness on the part of all to take one another's points of view seriously.

As we have seen, rights are also thought of as claims against society, against the community. The view proposed here is that as institutionalized social relations rights can exist only within communities and by the authority of those communities (that is, by the joint authority of their members). Operative rights are mutual relations among the members of those communities, not between a member and the community itself. Even a right such as the right to vote is an entitlement that all the members of the community are mutually obligated to respect and to implement as well as one in which they share. If and when a governmental body enforces the implementation of this or any right, it is acting in the name and by the authority of its members, who share the obligation to see that it is implemented. For a community to have rights qua community is, as I shall show, for it to participate as a member of a wider community in rights-relations that are similarly those of mutual entitlement and mutual obligation.

Before ending this section, I should like to point out that the rights-relation is a reflexive as well as an interpersonal one. Since each role is defined in terms of the other, nobody can have the attitude proper to one without at the same time having the attitude proper to the other. To claim a rights-entitlement, or even to recognize that one has it, is at the same time to express not only respect for that entitlement but recognition of the obligatory 
character of this respect. This is as true in relation to one's own claims as it is in relation to those of others.

\section{Essentialism}

Surprising as it may sound, as social institutions, rights are really traits of the communities in which they are operative, not of persons. In the strict sense of this term, it is not rights as such that members of a community have when rights are institutionalized there, but rights-entitlements and rights-obligations. Since these are operative only in the life of a community, it would seem that we have to seek the ground of rights in the nature of community or in the requirements of social interaction rather than in individual human nature or some feature thereof. Mead sees the mutual recognition of rights to be the expression of the attitude of a generalized other and, hence, to be a form of community. Agreeing with him, I agree as well that this attitude is generated in the effort to guide and direct the social process as such and the contributions of individuals to it. Thus, it seems to me that the institution of rights is grounded in, and rights are justified by, the requirements of social interaction. All social norms evolve out of the need of individuals to organize and coordinate their behavior, which requires them to know what to expect of others and what others expect of them as well as to have common purposes and goals and a shared understanding of these. In this process, among the norms that evolve are standards and values. Rights-norms, which themselves express value judgments, would seem to arise as ways of regulating the mutual relations of individuals in pursuit of their own goals and their other values-in pursuit, that is, of those things, statuses, liberties, powers, and so on, that have come to be judged valuable by the community and by those individuals themselves.

This does not mean, however, that there are no criteria for participation in rights. Participation presupposes the ability to internalize and govern oneself by social norms, and, in particular, to govern oneself by rights-norms: not only to respect rightsentitlements but to recognize and accept the obligation to do so, as well as to acknowledge others as having the same entitlements and to hold them, too, obligated to respect them. The ability to 
internalize and govern oneself by its norms is a necessary condition of membership in any normative community; the rest are specific to participation in the institution of rights. So neither human nature itself, nor any of the human characteristics taken by more conventional theorists to be the ground of rightspersonhood, rationality, moral rationality, the power of agency, being a moral agent or a moral subject, being a project-pursuer, having interests-is specific enough to be the relevant criterion. The capacity for agency or rational or moral agency - the pursuit of projects - may be necessary conditions of rights behavior, but they are too general to be sufficient conditions, as is "humanity" (even if there is a universal human nature rather than indefinitely many characteristics that are typical of human beings but not necessarily shared by all). The contention that human beings and other animals have inherent value, and that this is the ground of rights, which is what Peter Singer asserts, is vulnerable on two counts. In the first place, as I have already pointed out, value is a judgment. As John Dewey would say, a value is a valuation, not a natural property. It is not inherent in any being. And even if it were, having inherent value would not confer upon the being possessed of it the powers that would enable it to participate in rights.

In the second place, rights are not traits of human nature, entailed by other traits, but modes of behavior, institutionalized ways in which the members of a community behave toward one another and which must be learned. Actual participation in this behavior, in rights-relations, does have prerequisites. Thus, it presupposes the fully developed ability to govern oneself by rightsnorms and rules out (human) fetuses and even newborns. Even if, as the defenders of fetal rights contend, fetuses (or even fertilized human ova) are human persons, they still do not have the powers of normative self-governance or the ability to respect rights-entitlements that are exercised in rights-relations. If we consider that which benefits something as being in its interest, we can admit that fetuses have interests, as Feinberg maintains they do. Granted all of this, human fetuses are still only possible or potential rightsparticipants, not actual ones. It is this distinction that Feinberg, who attributes rights to future generations as well as the unborn, misses, and I think he does so because he thinks of rights as prop- 
erties rather than as activities in which we engage together with others. On the other hand, the fact that normal newborns have the potentiality to develop into rights-participants is of singular importance. If they are treated as such, as having both rightsentitlements and the obligation to respect them, they will learn the attitudes and behaviors proper to those roles; they will come to internalize and govern themselves by rights-norms. For this reason they should be so treated. The learning that takes place, because it is active and not merely learning about rights, will result in the attitude of the community becoming part of the child's own attitude or perspective as a self.

\section{Individualism}

Individuals can have rights-i.e., rights-entitlements and rightsobligations-but they cannot have them in isolation from other individuals any more than they can have them in isolation from the communities in which those rights are institutionalized. As we have seen, a right is inherently relational and reciprocal. To "have a right" is to be involved in such a relation with others, not to have a property that belongs to one independently. Not only are the roles in a rights-relation reciprocally defined-even though in principle one has both roles, actualization of the right always presupposes a party who is entitled and one who implements the obligation to honor that entitlement; each member of the community in which the right is operative is empowered to play the one role and required to play the other whenever circumstances make either of these appropriate-but enactment of either role requires enactment of the other as its complement. Even the exercise of liberties involves respect by others; those who deny that there is any duty or obligation correlative to a liberty overlook the fact that, to be a right, a liberty must be institutionalized. What it means for a liberty to be institutionalized as a rights-entitlement is precisely that all the members of a community are obligated to refrain from interfering with it, an obligation that may be expressed in laws specifying that this liberty is to be protected. If the obligation is not recognized and accepted as such, one may be free to act in a particular way at any given time or place, but this freedom is not a right. Perhaps no 
one will interfere with it now, but there are no strictures against interfering with it the next time. (On the other hand, it should be noted that even if it is written into law, if the obligation to respect this freedom is not recognized and accepted in practice, no such right is operative.)

It is my contention that communities, too, can have rights; that, like individuals, at least some communities have the powers that enable them to participate in rights-relations. As we have seen, there are theorists who rule out community rights because they deny the reality of communities themselves. They see the existence of communities as posing an ontological problem because they are composed of individuals, and they therefore take them to be reducible to those individual members whom they view as independent existents (unlike an organism, which is not reducible to its component cells because they are not independent individuals). But if we accept the idea that anything that is efficacious, that in any way makes a difference, is real, communities are undoubtedly real. The attitude or perspective shared by those who regulate their interactions by it, the perspective Mead calls the attitude of a generalized other, is one means by which a community is efficacious. (I prefer the term 'perspective', which seems to me to be more inclusive than 'attitude'.) The perspective of a generalized other is not identical with the personal perspective of any single member or of them all together; produced by them jointly, it is a perspective that they share, but that is only one component of their personal perspectives. Insofar as they share it, and only insofar as they do, these individuals constitute a community, which is something over and above what they would be as isolated or independent individuals who did not share in this attitude.

Participation in rights is participation in relations with others. For a community to do this would require it to share in a perspective which was that of a wider community, a perspective that includes rights-norms; it would also require the community (and all the other members of the more inclusive community) to be able to govern itself by those norms, to respect as well as have rights-entitlements, and to express this respect in action. All of this presupposes that a community can judge and act as a body; 
that it not only is efficacious in the sense specified, but can function agentially.

First of all, communities do belong to more inclusive communities, which is to say that any number of communities can have elements of their perspectives, including norms, in common. Second, any community that can produce a vote or somehow arrive at and express consensus has a voice and can participate in dialogue with others; any community whose members can generate a decision that their community is to be bound by a norm or law or decision of a more inclusive community, and any community capable of electing a representative to speak or to act in its name, is able to function as an agent. Whether by vote or (in the case of small communities) by consensus, a community can install norms extending rights to all the members of an inclusive community as components of its perspective as a community; by the same means, it can acknowledge as well as exercise entitlements, can accept the obligation to respect them and implement that respect when called upon, and can call upon other communities to do so. In so doing it is engaging in rights-relations with those other communities.

There are some communities that can participate in rights-relations with individuals. A corporation, for instance, is a particular sort of organized community, and can enter into contracts both with other corporations or communities of other kinds (a city, for instance) and with individuals (customers, clients, or suppliers, or even their own employees). Under the norms defining and governing contracts, both parties to a contract are alike entitled to have its provisions carried out and are alike obligated to do so, even though the provisions of the contract assign different specific entitlements and obligations to each. And if either were in the position of the other, it would have the other's entitlements and obligations. Every individual member of a community in which the right of contract is operative should have internalized the norms governing that right; every subcommunity of that community, companies and corporations in particular, should similarly govern itself by those norms; i.e., they should be included among the rules and principles in terms of which it operates. The norms governing the right of contract (or any comparable right) may be written into law, or stated in the manuals or other documents by 
which the activities of participating subcommunities are controlled. But whether or not they are formally stated, where the institution of contract exists, individuals and subcommunities alike must govern themselves by the same norms.

Moreover, there are rights in which communities ought to participate. It follows from the definition of a right that no member of a community should be denied any of the rights that are operative there. By the same definition, this applies not only to individuals but also to the subcommunities that are the members of an inclusive community. For instance, a right of sovereignty institutionalized in a community of nation states cannot be denied to any member of that community without negating it, without denying that it is really a right. Beyond this, to affirm a right, as Mead can be understood to be saying, is to affirm the intention to extend both the entitlement and the obligation to respect it to all; so that for a right to be institutionalized is for the members of the community in which it is operative to commit themselves to its universalization, even if that right is not in fact (as it is unlikely to be) universally operative. Again, this is as true for the members of a community of communities as it is for a community of individuals. To assert the existence of a right or to claim to have a right is to say implicitly not only that anyone who has internalized the norms governing that right knows he or she ought to respect it and to require others to respect it as well, but also that any individual or any community that is similarly situated ought to have the same right. Most important, since the necessary conditions of community are also prerequisites of the existence and stability of a community of communities, those rights I have identified as fundamental and generic ought to be operative for all the (sub)communities of every inclusive community. Each should be equally entitled to participate in the affairs of that inclusive community as an autonomous and authoritative agent.

The principle that no rights should be selectively denied the members of any community entails another sort of right, closely related to what I am calling community rights. On my definition of a right, no individuals should be selectively denied any rights operative in their community or communities, so that none should be denied the fundamental generic rights on the basis of their membership in any particular subcommunity. That is, no 
individuals should be excluded from participating in rights on the basis of their collective identity. Thus, in addition to the rights they have or ought to have as individuals, the members of every (sub)community within a wider community should have a collective entitlement to equal treatment: an entitlement to participate in all the rights accorded the members of any other subcommunity of their parent community. This right of equal treatment, which the members of each subcommunity, collectively as well as individually, are also obligated to respect, has its most significant application in the case of ethnic minorities. But it should be operative in and for every community, whatever its constitution.

\section{Notes}

1. Wesley Newcomb Hohfeld, Fundamental Legal Conceptions, ed. W. W. Cook (New Haven, Connecticut: Yale University Press, 1919), p. 38.

2. Judith Jarvis Thomson, The Realm of Rights (Cambridge, Massachusetts: Harvard University Press, 1990), p. 41.

3. Alan Gewirth, Human Rights: Essays on Justification and Applications (Chicago and London: The University of Chicago Press, 1982), p. 49.

4. Joel Feinberg, "The Nature and Value of Rights," in Rights, ed. David Lyons (Belmont, California: Wadsworth, 1979), p. 90.

5. Virginia Held, Rights and Goods: Justifying Social Action (New York: The Free Press, 1984), p. 15.

6. On affirmative action, see, for example, Bernard R. Boxill, Blacks and Social Justice (Totowa, New Jersey: Rowman and Allanheld, 1984); Ronald Dworkin, A Matter of Principle (Cambridge, Massachusetts: Harvard University Press, 1985), Part Five, "Reverse Discrimination"; Gertrude Ezorsky, Racism and Justice: The Case for Affirmative Action (Ithaca, New York: Cornell University Press, 1991).

7. George Herbert Mead, too, speaks in terms of the obligation to respect a right rather than in terms of duties; see, for example, Movements of Thought in the Nineteenth Century, ed. Merritt H. Moore (Chicago: The University of Chicago Press, 1936), p. 13; hereafter cited as MT.

8. Margaret MacDonald, "Natural Rights," Proceedings of the Aristotelian Society (1947-48), repr. in Theories of Rights, ed. Jeremy Waldron (Oxford: Oxford University Press, 1989). 
9. I take the term 'dialogic reciprocity' and the basic idea of a community of dialogic reciprocity from Drucilla Cornell, "Two Lectures on the Normative Dimensions of Community in the Law," second lecture, "In Defense of Dialogic Reciprocity," Tennessee Law Review, 54 (1987), 335-343. 